\section{Leaking gas and greenhouse}

SIR - Max K. Wallis (Nature 354, 428; 1991) claims that accelerated replacement of gas mains would be a costeffective means of reducing greenhouse gas emissions. Unfortunately, his argument is based on a series of erroneous assumptions about the amount of gas leakage and the costs of replacing mains and services.

The UK Department of the Environment estimates show coal-mining as the major source of methane emissions. Its latest estimates, for 1989 , show that gas leakage from the distribution system accounted for 340,000 tonnes of methane (Hansard, 11 November 1991, Written Answers, col. 390). Using Wallis's conversion factor, this comes to 170 million therms - very different from the 908 million therms "avoidable leakage" he assumes.

The length of pre-1969 mains still in use is $100,000 \mathrm{~km}$, not $140,000 \mathrm{~km}$. Wallis was told this by British Gas in August 1990 and November 1991, and I fail to understand why he uses a much higher figure which he knows is not accurate. It is also a matter of fact that a considerable proportion of the 100,000 $\mathrm{km}$ was not laid with hemp-lead joints, because this technique was discontinued long before 1969. British Gas also denies the implication that gas conditioning to reduce leakage is "hardly effective" for low-pressure mains. Considerable amounts of money are spent on this activity which forms a major part of the leakage control programme.

Furthermore, Wallis has misunderstood the figures he has taken from the company's annual report and accounts for 1990, and in doing so has grossly underestimated the true costs of replacing both mains and services.

His assumptions are thus very far removed from the true figures. They do not add to the well-established case, accepted by responsible gas suppliers such as British Gas, for retaining a programme of replacing mains and services. This is justified by the need to maintain public safety and security of supply. Over the past ten years, the number of serious gas explosions has

\section{Hit or miss?}

SIR - Fortunately for us all, the encounter described by Scotti et al. (Nature 354,287 ; 1991) was not, as characterized by the authors, a "near miss of the Earth by a small asteroid" but was, rather, a near hit.

STEPHEN E. SCHWARTZ Brookhaven National Laboratory, Upton, New York 11973, USA halved, while the amount of gas consumed has increased by more than 15 per cent; and British Gas has relaid $30,000 \mathrm{~km}$ of mains and replaced more than 4 million services, mostly using welded polyethylene pipe which is virtually leak-free.

There is no need for arguments about the greenhouse effect based on erroneous assumptions. The maintenance of a safe, reliable and economic system of gas supply will always require that gas leaks be kept to a minimum, and that the replacement of mains and services should be a continuous planned activity; but there is no justification for a crash programme of total replacement. British Gas intends to continue with its massive programme of mains replacement, to keep the public informed about its activities, and to counter the greenhouse effect by two means that are known to be effective: encouraging customers to conserve energy, and supplying gas in place of fuels that emit much higher levels of carbon dioxide.

British Gas,

R. HERBERT

152 Grosvenor Road,

London SW1V $3 J L$, UK

\section{Dirty habits}

SIR - James Vickers (Nature 353, 103; 1991) mentions the risks inherent in bottle-feeding where clean water is scarce and infection rife, M. F. Goldfarb stresses the problems resulting from mixing milk powder with poor-quality water. These statements reflect the prevalent dogma that infected water or baby foods are a major cause of infantile diarrhoea, that is, the problem is infected oral input. I have just received circulars from two charities: WaterAid states that dirty water kills 10 million babies and small children every year; CARE states that in a year 3.5 million children under five could have perished, victims of just one cause: diarrhoeal disease spread by dirty water.

Over many years, I have been checking published data after suspecting that airborne infection via latent otomatoiditis with secondary pulmonary and intestinal infections might be the main cause of postneonatal infant deaths. In The Lancet in $1981^{1}$ I claimed that there was no relation between contaminated milk or water supplies and infant gastroenteritis. This was not challenged ${ }^{2}$. In the Journal of the American Medical Association in 1986, I claimed that the crucial factor was how infants were fed, not what they were fed. One person disputed this ${ }^{3}$, but apart from making the obvious point that bacteria are ubi- quitous in developing countries, no convincing experimental or observational study directly linking contaminated food with infant diarrhoea was cited ${ }^{2}$, or has been produced since.

In view of the major health, economic and political implications of this dogma, it is unhelpful to keep asserting it, as it then becomes a self-evident truth which no one thinks even to test. It is a new form of cultural imperialism - or maybe the emperor has just got new clothes?

A. G. GORDON

32 Love Walk,

London SE5 8AD, UK

1. Gordon, A.G. Lancet II, 151 (1981)

2. Gordon, A.G. J. Am. med. Ass. 257, 3362 (1987).

3. Holland, B. J.Am. med. Ass. 257, 3361 (1987)

\section{Quality meetings}

SIR - Last July, the International Programme Committee of the International Union of Physiological Sciences (IUPS) met in Glasgow, to prepare the union's 32 nd congress. The meeting was well organized and productive, anticipating a success for the IUPS meeting in 1993.

But a question arose which in my experience, is not limited to a given scientific area or to a working group: how is it possible to assure the highest scientific quality of a 'world congress' and at the same time have a fair geographical representation? This is particularly important for scientists working outside North America and Western Europe who want to share their experiences with their colleagues. Taking the IUPS as an example, about 4 per cent of those in the World Directory of Physiologists are Latin Americans, a figure that roughly agrees with the written production of Latin American scientists in the life sciences (Current Contents, Life Sciences, Issues 19 \& 20; 1984). However, fewer than one in a thousand lectures and symposia speakers came from this geographical area during the last meeting in Helsinki (Proc XXXI IUPS Congress, 1989).

A simple and feasible answer has to embrace both aspects of the question. First, quality: invited speakers should be selected from among the best, taking into consideration as an objective index their publications.

Second, a fair geographical distribution among the potential speakers who publish in leading international journals: why should scientists working outside North America and Western Europe not have the opportunity to discuss the same results as are accepted for publication?

CARLOS LIBERTUN

Laboratory of Neuroendocrinology,

Instituto de Biologia

y Medicina Experimental,

Obligado 2490 ,

1428 Bueno Aires, Argentina 